\title{
Assessment of Genetic Diversity in Thirty-Five Genotypes of Oilseed Brassica Species using Principal Component Analysis
}

\author{
M.C. Gupta ${ }^{1}$, A.K. Sharma ${ }^{1}$, A.K. Singh ${ }^{1}$, Himadri Shekhar Roy $^{2}$ and \\ Sudhir Singh Bhadauria ${ }^{3}$
}

${ }^{1}$ Department of Plant Breeding \& Genetics, College of Agriculture, Gwalior-474002 (MP), India

${ }^{2}$ Department of Statistical Genetics, IASRI, Library Avenue, Pusa, New Delhi-110012, India

${ }^{3}$ Department of Agronomy, College of Agriculture, Gwalior-474002 (MP), India

*Corresponding author

\section{A B S T R A C T}

\section{Keywords}

Principal component, Cluster, Genotypes, variable, Brassica

Article Info

Accepted:

04 December 2018

Available Online:

10 January 2019
The principal component and factor analyses of 35 genotypes of different Brassica species was carried for pooled data of two years 2015-16 and 2016-17. The PCA indicated that first four principal components showed eigen values more than one and explained more than $80 \%$ of total variability in pooled analysis. Based on Varimax Rotation all fourteen characters were grouped in eight principal factors and siliquae per plant, plant height, main shoot length and siliquae on main shoot were the major contributing traits which accounted for $69.33 \%$ of total variation of $82.46 \%$. The hierarchical cluster analysis divided 35 genotypes into six clusters. The cluster IV appeared as the largest cluster containing maximum numbers of genotypes 23 under pooled analysis. The mean performance of different clusters revealed wide range of differences among clusters. The genotypes V20 (GPM-O-1 X PT-303), V16 (PL-58 X BN-11), V27 (GPM-O-58), V5 (NGM-17 X T-42) and V15 (PL-58 X BN-10) in cluster IV showed very good performance for seed \& oil yield per plant. While genotypes V11 (T-42 X NGM-17), V10 (T-42 X GPM-O-58), V19 (T-42 X PL-58) and V33 (T-42) in cluster III, IV and V exhibited very good performance for oil content.

\section{Introduction}

Rapeseed-mustard is the second most important edible oilseed crop in India after Soybean. It contributes about $23 \%$ and $25 \%$ in the total oilseed area and production, respectively. It is grown over an area of 6.5 million ha with production and productivity of 7.28 million tons and $1128 \mathrm{~kg} / \mathrm{ha}$, respectively
(Anonymous, 2015). Most of the mustard cultivars have very narrow genetic base which limits their further crop improvement. Genetic variability in respect to genetic diversity is the prerequisite for the crop improvement. Genetic diversity arises either due to geographical separation or due to genetic barriers to cross ability. The interspecific hybridization also could be one way to create 
genetic variability and broaden the genetic base. The quantification of genetic diversity by biometrical approaches can help in choosing diverse parents for a successful breeding programme. The principal component and factor analysis is an important tool for the assessment of genetic divergence among the genotypes and to assess the relative contribution of particular trait to the total variability. It also helps in identifying most relevant characters by explaining the total variation in the original set of variables with as few of the components as possible and reduces the complexity or dimension of the problem (Zaman et al., 2010). Thus, keeping all this in view, the present research work was planned to determine the importance of traits associated with seed and oil yield along with their inter-relationship and to cluster them using PCA analysis for all 35 genotypes of different oilseed Brassica species comprising $20 \mathrm{~F}_{2 \mathrm{~s}} / \mathrm{F}_{3 \mathrm{~s}}$ populations (designated as $\mathrm{V} 1$ to $\mathrm{V} 20$ ) and 15 parents (designated as V21 to V35).

\section{Materials and Methods}

The experimental material comprised of 20 segregating populations $\left(\mathrm{F}_{2} \mathrm{~S} / \mathrm{F}_{3} \mathrm{~s}\right)$ and 15 parents (Nine $B$. juncea lines, two $B$. napuslines, one line each of $B$. rapa var toria, $B$. rapa var. yellow sarson, $B$. carinata and $B$. nigra) Table 1 . These genotypes represented a very wide range of diversity available in the respective species. The segregating populations were derived by attempting interspecific crosses during rabi 2013-14. $\mathrm{F}_{1} \mathrm{~s}$ thus produced were planted during 2014-15. Colchicine treatment was given to sterile interspecific $\mathrm{F}_{1} \mathrm{~s}$. The $\mathrm{F}_{1} \mathrm{~s}$ were selfed to develop $F_{2}$ populations during rabi 2014-15. The $\mathrm{F}_{2} \mathrm{~S}$ were selfed to develop $\mathrm{F}_{3} \mathrm{~S}$ population. Twenty $\mathrm{F}_{2} \mathrm{~S} / \mathrm{F}_{3} \mathrm{~S}$ population along with fifteen parents were evaluated for two consecutive years Rabi 2015-16 and 2016-17 at research field, College of Agriculture Gwalior (MP)
India. The experiments were laid out in randomized block design with two replications at spacing of $45 \times 15 \mathrm{~cm}$ in paired rows. Ten plants from parent and 40 plants from $\mathrm{F}_{2} \mathrm{~S} / \mathrm{F}_{3} \mathrm{~s}$ were selected randomly for recording of various observations. Data for different agronomic and qualitative traits viz. days to $50 \%$ flowering (DF), plant height (PH), nos. of primary branches per plant (PB), nos. of secondary branches per plant (SB), main shoot length (MSL), siliquae on main shoot (SOMS), siliquae per plant (SPP), siliqua length (SL), seeds per siliqua (SPS), test weight (TW), days to maturity (DM), seed yield per plant (SYPP), oil content (OC) and oil yield per plant (OYPP) were recorded from randomly selected plants.

\section{Statistical analysis}

Principal factor and cluster analyses were performed using SPSS 10.0. Principal factor analysis was carried out using principal component method for factor extraction. The principal components (PCs) with eigen roots more than one were retained. As the initial factor loadings were not clearly interpretable, the factor axes were rotated using Varimax rotation. The correlation values $>0.5$ between the traits and the principal components were considered for construing the relationship between the traits, and the principal Factor (PF). Principal factor scores were calculated using Anderson-Rubin method. Scatter plots were drawn using two main Principal factors in order to identify the most distinct and useful accessions with desirable traits in different clusters. Unweighted Pair-Group Method using Arithmetic Averages Method (UPGMA) of hierarchical cluster analysis was utilized with city block distances to classify all 35 genotypes

For studying different genetic parameters and inter-relationships, fourteen characters were taken into consideration from the randomly 
selected 10 plants in parents and 40 plants in segregating population both years 2015-16 and 2016-17. Mean data of each character was estimated and pooled data of two years (201516 and 2016-17) was subjected to Principal Component Analysis (PCA).

\section{Results and Discussion}

\section{Eigen values and percent variance}

Principal component analysis indicated that only first four principal components (PCs) showed eigen values more than one and they cumulatively explained $82.46 \%$ of the total variability. The first PC (PC1) explained $36.69 \%$ of the total variation and the remaining three principal components explained 17.82, 14.83 and 13.13 variation, respectively (Table 2 ). The first one absorbed and accounted for maximum proportion of total variability in the set of all PCs and the remaining ones accounted for progressively lesser and lesser amount of variation.

\section{Factor loadings of characters with respect to principal factors (Varimax rotation)}

The analysis without rotation of axes could not load all the variables which indicated that it didn't offer much information regarding the idea of correlation between the variables and the principal components. The Varimax rotation, thus applied, resulted in loading of all the variables on different principal components. Factors' loadings of different variables are presented in Table 3. All fourteen variables showed high loadings on different principal factors, and none was left after rotation of the principal factor axes.

The first principal factor (PF-1) ascribed for number of siliquae per plant and it was designated as siliqua factor. The PF-2 had high loading for plant height and designated as height factor. Factor-3 had high loadings for two variables i.e. main shoot length and number of siliquae on main shoot, this factor was designated as main shoot factor. The PF-4 was named as siliqua and seed factor as two variables viz. number of siliquae on main shoot and seeds per siliqua were loaded on this factor. Variables seed per siliqua, siliquae on main shoot and seed yield plant were loaded on the principle factor- 5, hence it was designated as seeds factor. PF-6 was designated as maturity factor as variables viz. days to $50 \%$, flowering and days to maturity were loaded on this factor. Two variables viz. seed yield per plant and secondary branch were loaded on the principle factor- 7 hence it was designated as seed yield factor. The PF-8 had high loadings on variables secondary branches and seeds per siliqua and designated as branching factor.

\section{Clustering pattern based on UPGMA method}

Unweighted Pair-Group Method using Arithmetic Averages (UPGMA) of hierarchical cluster analysis was utilized with city block distances to classify the thirty-five genotypes into six clusters containing one to twenty-three genotypes.

The UPGMA method in hierarchical cluster analysis grouped 35 genotypes into six clusters (C), Table 4. Maximum number of genotypes i.e. 23 was grouped in Cluster IV (CIV). Four genotypes were grouped each in cluster I (CI) and cluster V (CV). Two genotypes were present in cluster III. Whereas, one genotype each was grouped in clusters $\mathrm{CII}$ and CVI.

\section{Cluster means and general means of different characters}

The cluster means and general means for various characters under pooled analysis have been presented in Table 5. The comparison of 
cluster means revealed that Cluster IV had the highest mean values for eight characters viz., secondary branch (10.41), main shoot length (70.62), siliquae on main shoot (52.96), siliquae per plant (320.31), test weight (5.41), seed yield per plant (16.02), oil content (39.29) and oil yield per plant (6.28). This cluster was able to lead in respect of the highest cluster mean values for maximum characters. Among 14 characters, this cluster stood first for 8 characters.

The cluster II obtained the highest cluster mean value for six characters viz., days to $50 \%$ flowering (41.25), primary branch (6.45), secondary branch (12.35), siliqua on main shoot (72.60), siliquae per plant (327.72) and days to maturity (135.50 days). Cluster $\mathrm{V}$ also showed highest mean values for different 6 characters viz. days to $50 \%$ flowering (39.31 days), plant height $(122.58 \mathrm{~cm})$, primary branch (6.84), siliqua length $(6.53 \mathrm{~cm})$, seeds per siliqua (36.94), and oil content (43.52\%).

The cluster I showed highest mean values for three characters viz. days to $50 \%$ flowering (36.94 days), plant height $(111.27 \mathrm{~cm})$ and days to maturity (131.56 days). Cluster III observed highest loading for three characters plant height $(170.51 \mathrm{~cm})$, siliqua length $(5.59$ $\mathrm{cm})$ and seeds per siliqua (19.23) while cluster VI also showed highest loading for variables primary branch (9.93) and secondary branch (24.23).

Principal component analysis indicated that only first four principal components (PCs) showed eigen values more than one and they cumulatively explained more than $80 \%$ of the total variability under pooled study. The first principal component absorbed and accounted for maximum proportion of total variability in the set of all PCs and the remaining ones accounted for progressively lesser and lesser amount of variation. Similar results have also been reported earlier by Zada et al., (2013),
Avtar et al., (2014, 2017), Ray et al., (2014), Neeru et al., (2015) and Verma et al., (2016). The Varimax Rotation was applied to estimate correlation between the variables and the principal components. This resulted in loading of all the variables on different principal components.

Based on similarities of variables all fourteen characters have been grouped in eight principal factors viz. siliquae per plant factor, height factor, main shoot factor, siliqua factor, seed per siliqua factor, maturity factor, seed yield factor and branching factor. Similar results were reported by Singh et al., (2010), Zada et al., (2013), Neeru et al., (2015) and Avtar et al., (2017). Such a grouping of similar type of variables having loaded on a common principal factor elaborates the successful transformation of fourteen interrelated variables into eight independent principal factors explaining $82.46 \%$ of the variability of the original set under pooled analysis.

It was observed from analysis that siliquae per plant, plant height, main shoot length and nos. of siliquae on main shoot were the major distinct variability contributing traits and accounted for $69.33 \%$ of the total variation. Thus, the successful transformation of fourteen morphological variables into four independent principal factors by means of grouping of similar type of variables on different principal factors elaborated and explained. These findings were in tune with those obtained by Neeru et al., (2015) in Indian mustard. The UPGMA method with City Block distances in hierarchical cluster analysis has divided the thirty-five genotypes into six clusters (C). The cluster IV appeared as the largest cluster containing maximum numbers of genotypes 22 and 23 under pooled analysis. The numbers of genotypes in clusters I, II, III, V and VI were 4, 1, 2, 4 and 1, respectively. 
Table.1 List of $\mathrm{F}_{2} \mathrm{~S} / \mathrm{F}_{3} \mathrm{~s}$ population and parents used in research experiment

\begin{tabular}{|c|c|c|}
\hline Genotype & Pedigree & Genomic constitution \\
\hline V1 & NGM-43 X PT-303 & B. juncea $\times$ B. rapa var toria \\
\hline V2 & NGM-17 X PT-303 & B. juncea $\times$ B. rapa var toria \\
\hline V3 & KM-11 X T-42 & B. juncea $\times$ B. rapa var yellow sarson \\
\hline V4 & NGM-6 X T-42 & B. juncea $\times$ B. rapa var yellow sarson \\
\hline V5 & NGM-17 X T-42 & B. juncea $\times$ B. rapa var yellow sarson \\
\hline V6 & PL-58 X PT-303 & B. juncea $\times$ B. rapa var toria \\
\hline V7 & PT-303 X GPM-O-5 & B. rapa var toria $x B$. juncea \\
\hline V8 & (PT-303XGPM-O-5) X GPM-O-5 & (B. rapa var toria $\times$ B. juncea) $\times$ B. juncea \\
\hline V9 & PT303 X GPM-O-5 & B. rapa var toria $x$ B. juncea \\
\hline V10 & T-42 X GPM-O-58 & B. rapa var yellow sarson $x$ B. juncea \\
\hline V11 & T-42 X NGM-17 & B. rapa var yellow sarson $x$ B. juncea \\
\hline V12 & PT-303 X B. nigra & B. rapa var toria $\times$ B. nigra \\
\hline V13 & PL-6 X BN-11 & B. juncea $\times$ B. napus \\
\hline V14 & PL-6 X BN-10 & B. juncea $\times$ B. napus \\
\hline V15 & PL-58 X BN-10 & B. juncea $\times$ B. napus \\
\hline V16 & PL-58 X BN-11 & B. juncea $\times$ B. napus \\
\hline V17 & BN-11 X PL-6 & B. napus $x$ B. juncea \\
\hline V18 & KM-11 X CRP-09 & B. juncea $x$ B. carinata \\
\hline V19 & T-42 X PL-58 & B. rapa var yellow sarson $x$ B. juncea \\
\hline V20 & GPM-O-1 X PT-303 & B. juncea $\times$ B. rapa var toria \\
\hline V21 & NGM-43 & B. juncea \\
\hline V22 & NGM-17 & B. juncea \\
\hline V23 & KM-11 & B. juncea \\
\hline V24 & NGM-6 & B. juncea \\
\hline V25 & PL-58 & B. juncea \\
\hline V26 & GPM-O-5 & B. juncea \\
\hline V27 & GPM-O-58 & B. juncea \\
\hline V28 & PL-6 & B. juncea \\
\hline V29 & GPM-O-1 & B. juncea \\
\hline V30 & $\mathrm{BN}-10$ & B. napus \\
\hline V31 & $\mathrm{BN}-11$ & B. napus \\
\hline V32 & PT-303 & B. rapa var toria \\
\hline V33 & $\mathrm{T}-42$ & B. rapa var yellow sarson \\
\hline V34 & CRP-09 & B. carinata \\
\hline V35 & Banarasi Rai & B. nigra \\
\hline
\end{tabular}


Table. 2 Total variance explained by different principal component among $20 \mathrm{~F}_{2} \mathrm{~s} / \mathrm{F}_{3} \mathrm{~s}$ populations and 15 parents of different Brassica species for pooled of years 2015-16 and 2016-17

\begin{tabular}{|c|c|c|c|}
\hline $\begin{array}{c}\text { Principal } \\
\text { component }\end{array}$ & Eigen value & $\begin{array}{c}\text { Per cent } \\
\text { variance }\end{array}$ & $\begin{array}{c}\text { Per cent cumulative } \\
\text { variance }\end{array}$ \\
\hline $\mathbf{1}$ & 5.135 & 36.68 & 36.68 \\
\hline $\mathbf{2}$ & 2.495 & 17.82 & 54.50 \\
\hline $\mathbf{3}$ & 2.076 & 14.83 & 69.33 \\
\hline $\mathbf{4}$ & 1.838 & 13.13 & 82.46 \\
\hline $\mathbf{5}$ & 0.765 & 5.46 & 87.92 \\
\hline $\mathbf{6}$ & 0.418 & 2.99 & 90.91 \\
\hline $\mathbf{7}$ & 0.415 & 2.96 & 93.87 \\
\hline $\mathbf{8}$ & 0.314 & 2.24 & 96.11 \\
\hline $\mathbf{9}$ & 0.180 & 1.29 & 97.40 \\
\hline $\mathbf{1 0}$ & 0.149 & 1.06 & 98.46 \\
\hline $\mathbf{1 1}$ & 0.111 & 0.79 & 99.25 \\
\hline $\mathbf{1 2}$ & 0.068 & 0.49 & 99.74 \\
\hline $\mathbf{1 3}$ & 0.036 & 0.26 & 100.00 \\
\hline $\mathbf{1 4}$ & 0.000 & 0.00 & 100.00 \\
\hline
\end{tabular}

Percent variation explained by first four components $=82.46$

First 4 principal component scores were used for clustering purpose

Table.3 Factor loadings of characters with respect to different principal factors (Varimax rotation) in 35 genotypes of different Brassica species

\begin{tabular}{|l|c|c|c|c|c|c|c|c|}
\hline \multicolumn{1}{|c|}{ Trait } & PF-1 & PF-2 & PF-3 & PF-4 & PF-5 & PF-6 & PF-7 & PF-8 \\
\hline Days to 50\% & 0.004 & 0.093 & -0.158 & 0.053 & 0.085 & 0.478 & -0.462 & 0.126 \\
\hline Plant height & 0.133 & $0.967^{*}$ & -0.124 & 0.029 & 0.046 & -0.157 & 0.006 & -0.008 \\
\hline Primary branch & -0.000 & -0.008 & -0.062 & -0.282 & 0.067 & 0.053 & 0.176 & 0.178 \\
\hline Secondary branch & 0.023 & 0.022 & -0.130 & -0.122 & -0.170 & 0.109 & 0.460 & $0.803^{*}$ \\
\hline Main shoot length & 0.030 & 0.124 & $0.739^{*}$ & $0.529^{*}$ & -0.282 & 0.229 & -0.002 & 0.125 \\
\hline Siliquae on main & 0.033 & 0.102 & $0.576^{*}$ & -0.703 & 0.356 & 0.161 & -0.012 & 0.034 \\
\hline Siliquae per plant & $0.988^{*}$ & -0.142 & -0.205 & 0.018 & 0.021 & -0.015 & -0.036 & 0.004 \\
\hline Siliqua length & -0.004 & -0.005 & 0.002 & 0.079 & 0.056 & 0.033 & 0.010 & 0.037 \\
\hline Seeds per siliqua & -0.041 & -0.067 & 0.006 & 0.372 & $0.805^{*}$ & -0.098 & -0.108 & 0.310 \\
\hline Test weight & 0.001 & 0.014 & 0.011 & 0.071 & 0.016 & 0.014 & 0.097 & -0.076 \\
\hline Days to maturity & 0.008 & 0.066 & -0.238 & 0.026 & 0.078 & $0.778^{*}$ & 0.120 & -0.173 \\
\hline Seed yield per & 0.033 & 0.012 & 0.041 & 0.123 & 0.233 & 0.104 & $0.702^{*}$ & -0.389 \\
\hline Oil content & -0.008 & -0.003 & 0.047 & 0.167 & 0.181 & -0.142 & 0.116 & -0.065 \\
\hline Oil yield per plant & -0.006 & -0.004 & -0.009 & 0.109 & 0.078 & 0.085 & 0.02 & 0.041 \\
\hline
\end{tabular}


Table.4 Clustering pattern of $20 \mathrm{~F}_{2} \mathrm{~s} / \mathrm{F}_{3}$ s populations and 15 parents of different Brassica species during under pooled analysis

\begin{tabular}{|c|c|c|}
\hline Cluster & Parents/population & $\begin{array}{c}\text { Nos of } \\
\text { lines }\end{array}$ \\
\hline CI & V3 (KM-11XT-42), V18 (KM-11X B. carinata), V23 (KM-11), V32 (PT-303), & 4 \\
\hline CII & $\mathbf{V 3 5}($ B. nigra $)$ & 1 \\
\hline CIII & V28 (BN-10), V30 (BN-11), & 2 \\
\hline CIV & $\begin{array}{l}\text { V1 (NGM-43XPT-3-03), V2 (NGM-17XPT-303), V4 (NGM-6XT-42), V5 (NGM- } \\
17 X T-42), \text { V6 (PL-58XPT-303), V7 (PT-303XGPM-O-5), V8 ((PT-303XGPM-O- } \\
5) \text { X GPM-O-5), V9 (PT-303XGPM-O-5), V12 (PT-303 X B. nigra), V13 (PL- } \\
\text { 6XBN-11), V14 (PL-6XBN-10), V15 (PL-58XBN-10), V16 (PL-58XBN-11), V17 } \\
\text { (BN-11XPL-6), V20 (GPM-O-1-1XPT-303), V21 (NGM-43), V22 (NGM-17), } \\
\text { V24 (NGM-6), V25 (PL-58), V26 (GPM-O-5), V27 (GPM-O-58), V29 (PL-6), } \\
\text { V31 (GPM-O-1) }\end{array}$ & 23 \\
\hline CV & V10 (T-42XGPM-O-58), V11 (T-42XNGM-17), V19 (T-42XPL-58), V33 (T-42) & 4 \\
\hline CVI & V34 (B. carinata) & 1 \\
\hline
\end{tabular}

Table.5 Cluster means vs general means for various characters in $20 \mathrm{~F}_{2} \mathrm{~s} / \mathrm{F}_{3} \mathrm{~s}$ populations and 15 parents of different Brassica species for pooled of two years

\begin{tabular}{|l|c|c|c|c|c|c|c|}
\hline \multicolumn{1}{|c|}{ Characters } & Cluster-1 & Cluster-2 & Cluster-3 & Cluster-4 & Cluster-5 & Cluster-6 & $\begin{array}{c}\text { General } \\
\text { mean }\end{array}$ \\
\hline $\begin{array}{l}\text { Days to } \mathbf{5 0 \%} \\
\text { flowering }\end{array}$ & 36.94 & 41.25 & 51.25 & 44.13 & 39.31 & 55.00 & 43.39 \\
\hline Plant height & 111.27 & 185.73 & 170.51 & 193.52 & 122.58 & 223.11 & 175.32 \\
\hline $\begin{array}{l}\text { Nos of primary } \\
\text { branches }\end{array}$ & 5.24 & 6.45 & 4.12 & 5.23 & 6.84 & 9.93 & 5.52 \\
\hline $\begin{array}{l}\text { Nos of secondary } \\
\text { branches }\end{array}$ & 9.41 & 12.35 & 4.10 & 10.41 & 3.61 & 24.23 & 9.61 \\
\hline Main shoot length & 57.55 & 52.96 & 60.37 & 70.62 & 53.40 & 44.20 & 65.32 \\
\hline $\begin{array}{l}\text { Siliquae on main } \\
\text { shoot }\end{array}$ & 40.71 & 72.60 & 43.85 & 52.96 & 40.54 & 37.25 & 49.73 \\
\hline Siliquae per plant & 244.52 & 327.72 & 172.50 & 320.31 & 119.15 & 242.52 & 278.20 \\
\hline Siliqua length & 4.98 & 1.25 & 5.59 & 4.91 & 6.53 & 4.98 & 5.04 \\
\hline Seeds per siliqua & 15.16 & 4.82 & 19.23 & 14.80 & 36.94 & 12.52 & 17.28 \\
\hline Test weight & 3.73 & 1.17 & 4.03 & 5.41 & 4.52 & 4.60 & 4.89 \\
\hline Days to maturity & 131.56 & 135.50 & 137.38 & 136.39 & 132.62 & 150.00 & 135.83 \\
\hline Seed yield per plant & 9.98 & 8.88 & 7.01 & 16.02 & 9.84 & 12.20 & 13.79 \\
\hline Oil content & 36.46 & 33.83 & 38.86 & 39.29 & 43.52 & 35.50 & 39.16 \\
\hline Oil yield per plant & 3.64 & 3.00 & 2.72 & 6.28 & 4.30 & 4.32 & 5.40 \\
\hline
\end{tabular}


This analysis further showed that some of the genotypes belonging to various interspecific populations $\left(\mathrm{F}_{3} / \mathrm{F}_{2}\right)$ and their parents were grouped into the same cluster, while many others fell into different clusters. This clustering pattern suggests that interspecific diversity does not necessarily represent genetic diversity; this might be due to free exchange of genetic material among different species and also due to natural and artificial selection forces resulting in perpetuation and stabilization of similar genotypes. These results were in agreement with the results reported earlier by Budhanwar et al., (2010), Belete et al., (2011), and Singh (2012), Doddabhimappa et al., (2010), Singh (2012), Neeru et al., (2015) and Avtar et al., (2017).

In the present study, the mean performance of different clusters revealed wide range of differences among clusters (Table 5). The genotypes V20 (GPM-O-1 X PT-303), V16 (PL-58 X BN-11), V27 (GPM-O-58), V5 (NGM-17 X T-42) and V15 (PL-58 X BN-10) in cluster IV showed very good performance for seed and oil yield per plant due to possession of more numbers of siliquae per plant, long main shoot length, more siliquae on main shoot, more seeds per siliqua and higher test weight. While genotypes V11 (T42 X NGM-17), V10 (T-42 X GPM-O-58) and V19 (T-42 X PL-58)in cluster III and IV\& V33 (T-42)in cluster $\mathrm{V}$, respectively exhibited very good performance for oil content and could be used as donor for the introgression of high oil content. Alemayehu and Becker (2002) found that both principal component and cluster analyses disclosed complex relationships among the Ethiopian mustard (Brassica carinata A. Braun) accessions and characters. Similar results were reported by Singh (2012), Zaman et al., (2010), Singh et al., (2010), Avtar et al., (2017) and Nerru et al., (2015).

The results of this study concluded that the sufficient variability was existed in the material. All the 35 genotypes (20 $\mathrm{F}_{3} \mathrm{~s} / \mathrm{F}_{2} \mathrm{~S}$ population and 15 parents) have been successfully classified into six clusters and all the variables have been reduced to only eight principal factors. Based on mean performance of different clusters for different traits the genotypes V20 (GPM-O-1 X PT-303), V16 (PL-58 X BN-11), V27 (GPM-O-58), V5 (NGM-17 X T-42) and V15 (PL-58 X BN-10) were having high seed yield per plant and yield contributing components. The genotypes with superior oil content were V11 (T-42 X NGM-17), V10 (T-42 X GPM-O-58), V19 (T-42 X PL-58) and V33 (T-42) which can be utilized for evolving mustard varieties with high seed yield and oil content.

\section{Acknowledgement}

We gratefully acknowledge support received from the College of Agriculture Gwalior (MP) for carrying out this study. We are also thankful to Rasi Seeds for providing source materials for experiment.

\section{References}

Alemayehu Nigussie and Becker Heiko (2002). Genotypic diversity and patterns of variation in a germplasm material of Ethiopian mustard (Brassica carinata A. Braun). Genetic Resources and Crop Evolution49: 573-582.

Avtar R, Manmohan, MinakshiJattan, Babita Rani, Nisha Kumari, N. K. Thakral and R. K. Sheoran (2017). Evaluation and diversity analysis in Indian mustard [Brassica juncea (L.) Czern\&Coss.] germplasm accessions on the basis of principal component analysis. Journal of Applied and Natural Science 9(4): 2485 - 2490.

Avtar, R., Singh, D., Thakral, N.K., Singh, A., Sangwan, O., Rani, B. and Kumari, N. (2014). Multivariate 
analysis for evaluation and classification of toria germplasm accessions. Res. Crops 15(1): 129134.

Belete YS, Kebede SA and Gemelal AW. 2011. Multivariate analysis of genetic divergence among Ethiopian mustard (Brassica carinata A. Braun) genotypes in relation to seed oil quality traits. Intern J Agric Res 6: $494-503$.

Budhanwar PD, Kalamkar, Beena Nair, Vandana and Fulkar PI. 2010. Evaluation of recombinant lines for genetic potential and genetic diversity for yield contributing characters in mustard [B. juncea (L.) Czern\&Coss.]. Advances in Plant Sci 23: 227-229.

Doddabhimappa, R., Gangapur, B., Prakash, G. and Hiremath, C. P. (2010). Genetic Diversity analysis of Indian mustard (Brassica juncea L.) Electro. J. Plant Breed. 1(4): 407-413.

Neeru, Thakral, N. K., Avtar R., and Singh A. (2015). Evalu-ation and classification of Indian mustard (Brassica juncea L.) genotypes using principal component analysis. J. Oilseed Brassica 6(1), 167-174.

Romesburg, H.C. (1984). Cluster Analysis for Researchers. Krieger Publishing Co., Malabar, Florida.

Rray K, J. Dutta, H. Banerjee, R. Biswas, A. Phonglosa and A. Pari (2014). Identification of principal yield attributing traits of Indian Mustard [Brassica juncea (L.) Czernj and Cosson] using multivariate analysis. The Bioscan 9(2):803-809

Singh D, Arya RK, Chandra N, Niwas R and Salisbury P. 2010. Genetic diversity studies in relation to seed yield and its component traits in Indian mustard [Brassica juncea (L) Czern\&Coss.]. J Oilseed Brassica 1: 19-22.

Singh, B. (2012). Genetic divergence in elite genotypes of Indian mustard (Brassica juncea L.). M.Sc. Thesis; CCS HAU, Hisar.

Verma Urmil, N. K. Thakral and Neeru (2016): Genetic Diversity Analysis in Indian Mustard [Brassica Juncea (L.) Czern\&Coss.]. International Journal of Applied Mathematics \& Statistical Sciences (IJAMSS) Vol. 5, Issue 1

Zada, M., Zakir, N., Rabbani, M., Shinwari, A. and Khan, Z. (2013). Assessment of genetic diversity in Ethiopian mustard (Brassica carinata A. Brun) germplasm using multivariate techniques. Pak. J. Bot. 45(SI): 583593.

Zaman, M. A., Khatun, M. T., Ullah, M. Z., Moniruzzamn, M. and Rahman, M. Z. (2010). Multivariate analysis of divergence in advanced lines of mustard (Brassica spp) Bangladesh Journal of Plant Breeding Genet. 23(2):29-34.

\section{How to cite this article:}

Gupta, M.C., A.K. Sharma, A.K. Singh, Himadri Shekhar Roy and Sudhir Singh Bhadauria. 2019. Assessment of Genetic Diversity in Thirty-Five Genotypes of Oilseed Brassica Species using Principal Component Analysis. Int.J.Curr.Microbiol.App.Sci. 8(01): 378-386. doi: https://doi.org/10.20546/ijcmas.2019.801.039 